\title{
Evaluation of KTT-2 Pneumatic Peat Harvesting Machine's Nozzle Suction Capacity
}

\author{
Alexander Yablonev ${ }^{1, *}$, and Darya Scherbakova ${ }^{1}$ \\ ${ }^{1}$ Tver State Technical University (TvSTU), 22 Afanasy Nikitin Emb., 22, Tver, Russia, 170026
}

\begin{abstract}
Milled peat harvesting with pneumatic harvesting machines has a number of doubtless advantages over mechanical harvesting: operating time decreases down to 1 day, additional milling of wet peat deposit during the harvesting is not needed, list of necessary machinery decreases. However, in the late 1980s, due to the imperfection of the design of pneumatic machines, this method began to be used less and less frequently. Market appearance of KTT-2 and MPTU-30 pneumatic harvesting machines promoted their introduction into operating processes of peat extractive companies. According to feedback from operators, these machines work well with high-moor peat but work much worse with lowmoor peat which is of higher density. One of basic parameters of pneumatic harvesting is suction velocity, that's why field experiment for evaluation of KTT-2 machine suction nozzle performance was held. Experiment results enabled us to plot velocity diagram of suction flow and find maximum suction velocity: $26.74 \mathrm{~m} / \mathrm{s}$. Velocity diagram analysis showed distance from the nozzle - air flow speed relation. We calculated size of suction flow's active area and offered methods of active area sizing.
\end{abstract}

\section{Introduction}

Russian milled peat and its products are in consistent demand both at inland market and abroad [1, 2, 3, and 4]. There are two methods of peat harvesting: mechanical and pneumatic one known since 1930s. Earlier self-driving and trailing pneumatic harvesting machines were made of ferrous metals and were heavy and of large size [5].

Obvious economic advantage of pneumatic harvesting is duration of peat production: only one day instead of two [6]. Reliability of this method was higher as one-day intervals of good weather conditions take place oftener than two-day ones [7]. But friction between fragmented peat and machine's inner walls generates static electricity which sometimes caused self-ignition and even explosions of such machines. That's why these machines fall out of favour in 1970s and 1980s. Nevertheless, since late 1990s this method revived (thanks to such companies as Canadian Premier Tech which developed trailing and selfdriving machines SA-200 and SAM-404 with parts made of stainless steel and aluminium alloy) because its peat loss is minimal [8], additional milling of wet peat deposit during the harvesting is not possible, list of necessary machinery is rather short [9].

\footnotetext{
*Corresponding author: alvovich@mail.ru
} 
In Russia nowadays there are no manufacturers of pneumatic harvesting machines, but some peat extractive companies purchased and use sister machines MPTU-30 manufactured in Byelorussia by Mogilevenergo and KTT-2 manufactured in Estonia by Kruviks OU. According to feedback from some peat harvesting companies, these machines fail to harvest some peat types (e.g., they have problems with harvesting of low-moor peat). That's why experiment took place, its aim being nozzle suction capacity evaluation of such machine operated at the enterprise Pindstrup in the Pskov Region.

\section{Method used}

In all above machines fragmented peat suction is performed with nozzles and is backed by difference between two pressures: vacuum gauge pressure generated by ventilator within the machine's pneumatics and ambient pressure. That's why ambient air is sucked into the nozzle and lugs away peat particles available in the suction flow area.

The longer is distance from the nozzle, the lower is air flow speed, hereby dividing suction flow area into two parts: active action area and passive action area. Researchers (L.O. Gortsakalian, etc., 1974, 1977) found necessary air flow speed at nozzle entry (25 to $35 \mathrm{~m} / \mathrm{s}$ ) and recommended simplified formula for evaluation of air flow speed $V_{x}$ in the point distance between which and the suction nozzle is equal to $x$ along suction flow axis:

$$
V_{x}=\frac{V_{o}}{1+\frac{10 x^{2}}{S}}
$$

where $V_{\mathrm{o}}$ is air flow speed in the nozzle wetted section; $x$ is distance between the point and the suction nozzle along the suction flow axis; $S$ is suction flow area's wetted section.

Air flow speed in the active area is enough to overcome frictional force and weight and to generate lift force for peat particle. In passive area lower air flow speed is not enough to generate lift force, so there is no suction. As a rule, beginning of the passive area is provided by air flow speed approximately 12 to $15 \mathrm{~m} / \mathrm{s}$.

Inside pneumatic machines, after suction nozzles peat particles pass areas of vertical and horizontal transportation as well as chamber of separation of peat-air mixture into peat and air. Peat particles' suspension velocity is very important parameter for transportation areas. This velocity depends on the particles' size, density and humidity and is determined by experiment. Chamber of fragmented peat/air separation of KTT-2 and MPTU-30 is not based upon cyclonic separation: it is a simple separator which operates due to pneumatic pipes' tangential entrance into the bowl and to significant increase of flow wetted section. As result, particles' speeds greatly decrease and particles gravitate to bowl's bottom.

As problems with harvesting of low-moor peat (which has greater density than highmoor peat) arise at suction phase, we decided to analyse velocity diagram of KTT-2 machine's suction flow.

Air speed was measured with portable anemometer GM8903 which is computercompatible and whose speed range is 0.3 to $30 \mathrm{~m} / \mathrm{s}$, accuracy of measurement being $\pm 3 \%$ (fig. 1). 


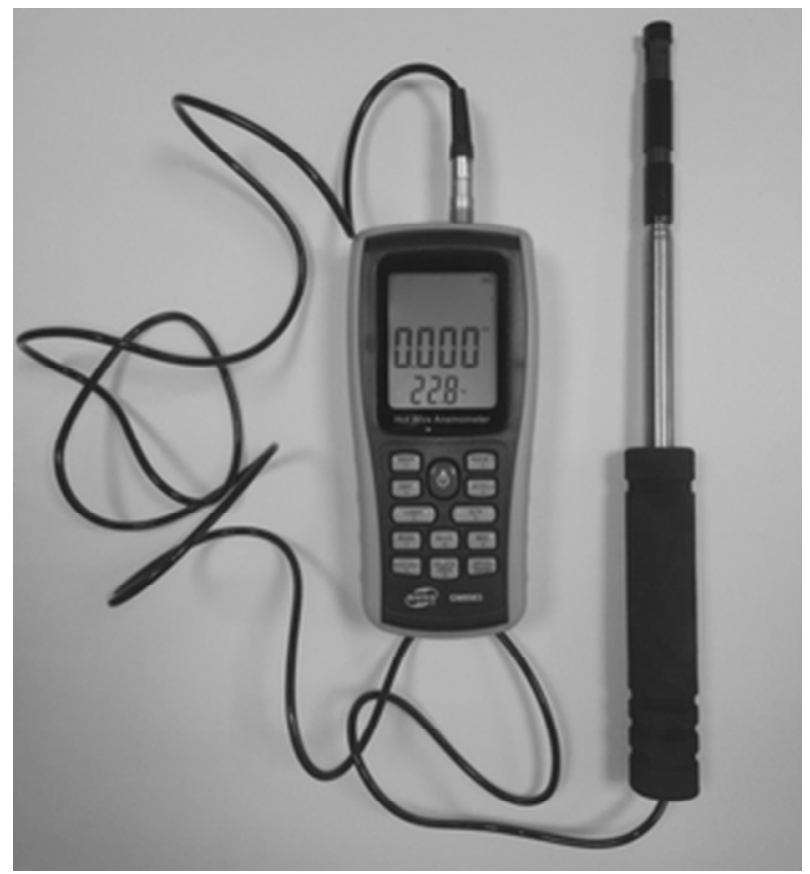

Fig. 1. Portable anemometer GM8903.

For research and for taking of speed readings of flow in front of suction nozzle, we used metal coordinate grid (mesh size $100 \mathrm{~mm}$ ). Appliance's outboard dipstick was fixed in grid nodes. All readings were taken with 5-time repeatability (fig. 2).

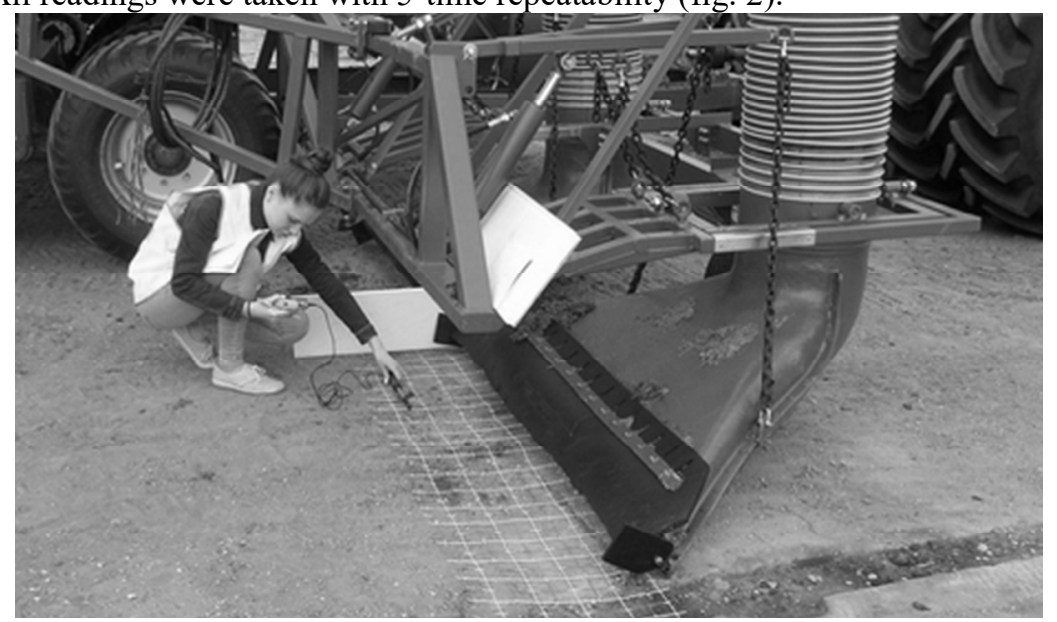

Fig. 2. Taking of air flow speed readings in front of the nozzle.

To evaluate influence of neighbouring nozzle on air flow speed, that nozzle was separated with air-proof partition. The air flow speed both influenced by neighbouring nozzle and not-influenced was logged in the experiment logbook. 


\section{Results and discussion}

Traditional measurement data mapping and calculation of suction diagram with isotachs is less informative than displaying of research results in two-axis plane with fixation of air flow speed values.

Results of measurements and calculation of arithmetic mean value based upon five measurements) are shown as coordinate along length of nozzle - air flow speed relation curve (fig. 3).

Due to limited size of the article, suction diagram of pneumatic harvesting machine's right nozzle is not shown. Such diagram will not show any new circumstances and trends, curves are essentially mirrored.

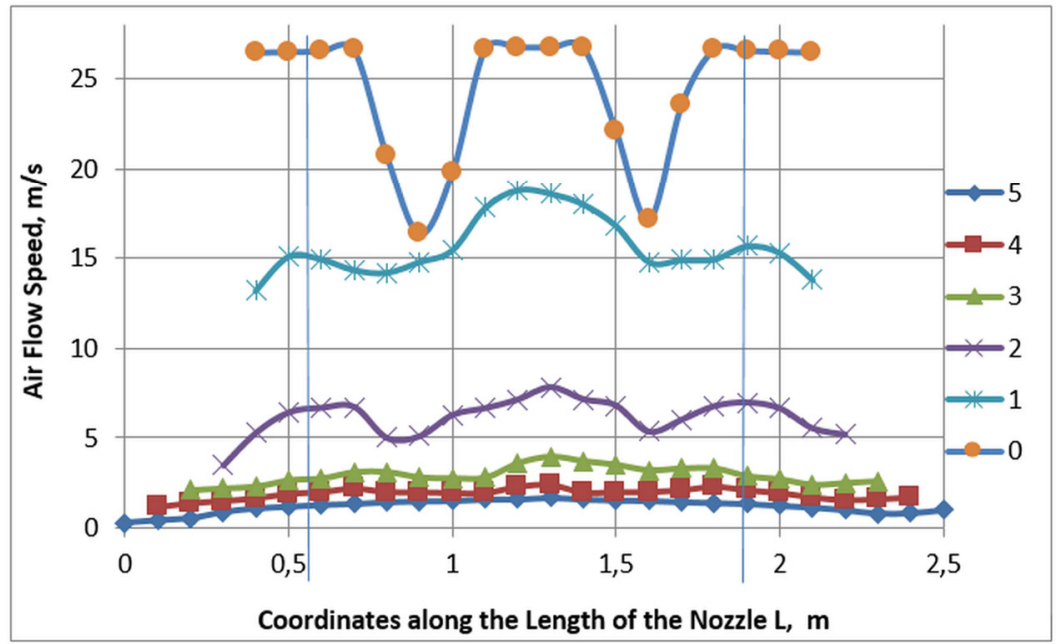

Fig. 3. Coordinate along length of nozzle - air flow speed (of KTT-2 left nozzle suction) relations: 0 - distance between the point and the nozzle along the suction flow axis (speed measured at the nozzle entrance); 1 - distance from the nozzle is $0.1 \mathrm{~m} ; 2$-distance from the nozzle is $0.2 \mathrm{~m} ; 3$-distance from the nozzle is $0.3 \mathrm{~m} ; 4$ - distance from the nozzle is $0.4 \mathrm{~m} ; 5$ - distance from the nozzle is $0.5 \mathrm{~m}$.

\section{Conclusion}

Analysis of relation curves displayed at fig. 3 showed: in all curves there are 2 air flow speed "drops" which can be explained by availability of air-proof reinforcing ribs connecting upper and lower edges of fibreglass nozzle (fig. 4).

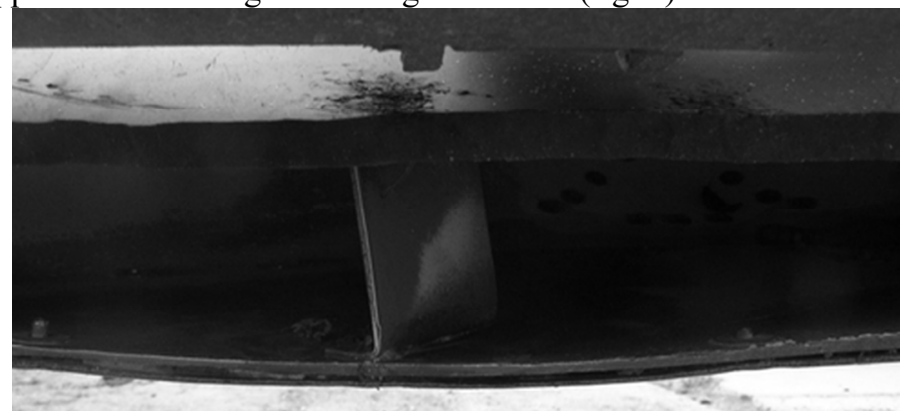

Fig. 4. Reinforcing air-proof rib connecting upper and lower edges of suction nozzle. 
The longer is distance from the nozzle, the smoother is relevant curve and the slower is air flow speed.

Slower air flow speed near the nozzle's vertical end walls is discovered also in all cases and can be explained by friction between flow and walls. Numerical values of air flow speeds near right side of the nozzle are somewhat higher than near left side, it can be explained with influence of air flow from the right nozzle. Air-proof partition between nozzles and speeds' measurements showed that in this case speeds at left and right sides of nozzle axis are the same.

Distance from suction nozzle - air flow speed relation curves (fig. 5) are plotted for three suction flow axes $(L=0.6 ; 1.3 ; 1.9 \mathrm{~m})$ (fig. 3 ). Coordinates of these axes are selected taking into consideration the decrease of nozzle vertical side walls' influence on air flow speed and the maximum air flow speed. The data were analysed and approximated with high accuracy $\left(R^{2} \geq 0.977\right)$ by exponential functions, for each of them there is mathematical model.

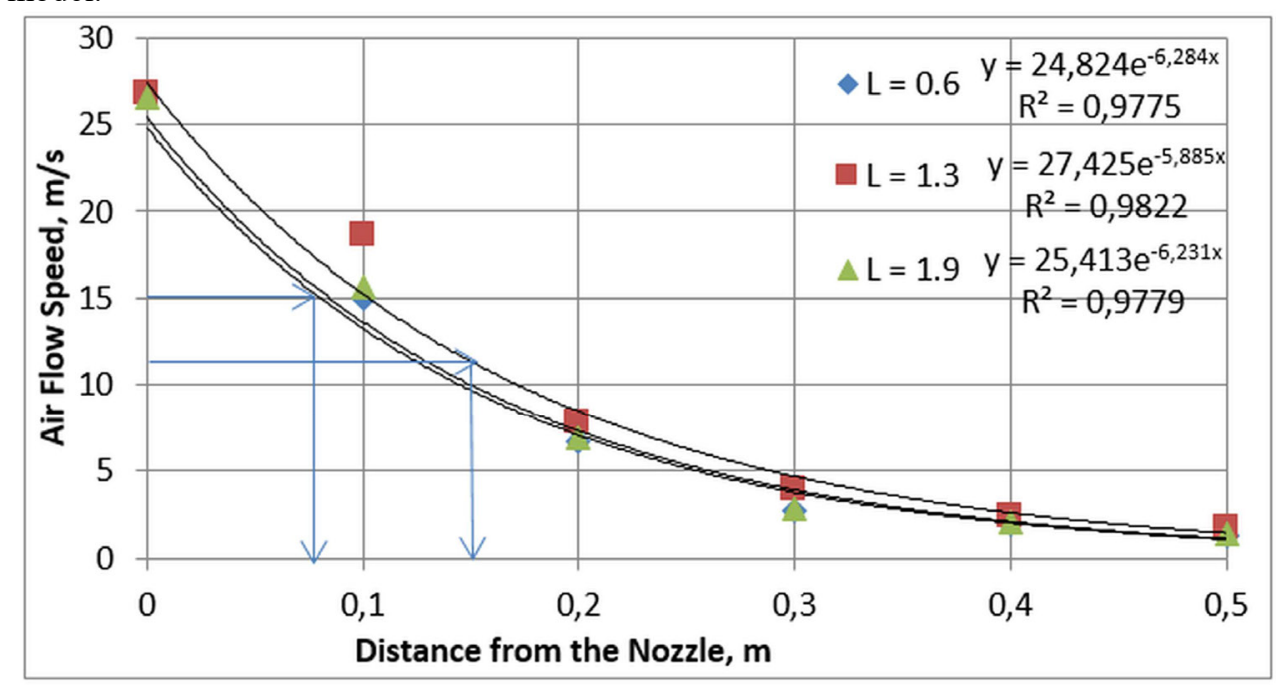

Fig. 5. Distance from the nozzle - air flow speed relation.

Air flow speeds obtained experimentally and calculated according to formula (1) were compared for the nozzle central axis $(L=1.3 \mathrm{~m})$. Between them we found relative divergence:

$$
\Delta=\frac{\left|V_{x}-V_{o f}\right|}{V_{x}} \cdot 100 \% .
$$

Results of experiments and calculation are shown in the table.

Beginning of suction passive area is limited with air flow speed 12 to $15 \mathrm{~m} / \mathrm{s}$. Taking it into consideration, according to fig. 5 suction flow active area length in such case is 0.078 to $0.142 \mathrm{~m}$. 
Table. 1 Experimental and calculated data of air flow speed in front of suction nozzle of KTT-2 pneumatic harvesting machine.

\begin{tabular}{|c|c|c|c|c|c|}
\hline \multirow{2}{*}{$\begin{array}{l}\text { Definable and } \\
\text { calculated } \\
\text { parameters } \\
\text { Distance } \\
\text { from nozzle } \\
\text { along the suction } \\
\text { flow axis, } m\end{array}$} & \multicolumn{3}{|c|}{$\begin{array}{l}\text { Speed } V_{\text {of }} \text { of air flow in the point with } \\
\text { coordinate along the length of the } \\
\text { nozzle } L\end{array}$} & \multirow{2}{*}{$\begin{array}{c}\text { Speed } \\
\text { calculated } \\
\text { value } V_{x} . \\
\mathrm{m} / \mathrm{s}\end{array}$} & \multirow{2}{*}{$\Delta, \%$} \\
\hline & $L=0.6 \mathrm{~m}$ & $L=1.3 \mathrm{~m}$ & $L=1.9 \mathrm{~m}$ & & \\
\hline 0 & 26.52 & 26.74 & 26.56 & 26.74 & 0 \\
\hline 0.1 & 14.95 & 18.6 & 15.67 & 17.05 & 8.84 \\
\hline 0.2 & 6.65 & 7.78 & 6.94 & 8.17 & 4.79 \\
\hline 0.3 & 2.75 & 3.95 & 2.87 & 4.37 & 9.69 \\
\hline 0.4 & 2.0 & 2.4 & 2.1 & 2.65 & 9.43 \\
\hline 0.5 & 1.3 & 1.7 & 1.35 & 1.76 & 3.35 \\
\hline
\end{tabular}

Experimentally obtained maximum suction velocity $\left(V_{1}=26.74 \mathrm{~m} / \mathrm{s}\right)$ and small active action area of suction flow confirm problems with harvesting of denser peat types. Way out of this situation and possible method of improving company's productive efficiency is increasing of maximum suction velocity and enhancement of suction nozzle's active action area. Analysis of Soviet pneumatic harvesting machines showed: height of their nozzles' entrance slits ranges from $0.05 \mathrm{~m}$ (BPF-2) to $0.08 \mathrm{~m}$ (PPF-3). Nozzle entrance slit height of the considered machine $h_{1}=0.1 \mathrm{~m}$, while wetted section area $S_{1}=a h_{1}=1.76 \cdot 0.1=0.176$ $\mathrm{m}^{2}$, where $a$ is nozzle's clamp length. We can approximately calculate maximum suction velocity for nozzle having same length and entrance slit height, e.g., $0.08 \mathrm{~m}$, cross section being $S_{2}=a h_{2}=1.76 \cdot 0.08=0.1408 \mathrm{~m}^{2}$. Then we use flow inseparability equation:

$$
V_{2}=\frac{V_{1} S_{1}}{S_{2}}
$$

and obtain result: $V_{2}=\frac{26.74 \cdot 0.176}{0.1408}=33.425 \mathrm{~m} / \mathrm{s}$. This suction velocity is much more distant from the minimal value $(25 \mathrm{~m} / \mathrm{s})$ than one provided by the design of KTT-2 machine. Such result will surely minimize problems with harvesting of denser peat types.

Active area enhancement of the suction flow is possible by means of special canopy installable at the nozzle's upper part. To plot this canopy's shape and size, additional laboratory research is necessary.

\section{Inferences}

Research of KTT-2 pneumatic harvesting machine suction flow is completed. Maximum $(26.74 \mathrm{~m} / \mathrm{s})$ and minimum values $(0.3 \mathrm{~m} / \mathrm{s})$ of air flow speed in the considered area are determined. Mathematical models describing distance from the nozzle - air flow speed relation are available. Divergence between experimental data and those calculated according to L.O. Gortsakalian's formula doesn't exceed $10 \%$ which is enough for engineering analysis. Active action area of the suction flow moving away from the nozzle is determined: it is 0.078 to $0.142 \mathrm{~m}$. As maximum value of suction velocity is rather low, it is recommended to increase it by means of reducing nozzle entrance slit height down to 80 $\mathrm{mm}$ and of enhancing suction active area. For the latter additional laboratory research is necessary. Air-proof reinforcing ribs essentially reduce suction flow, that's why it is useful to consider manufacturing of partially air permeable ribs whose longer sides should be located along the flow streamlines.

Alterations offered will promote increase in KTT-2 machine's performance due to increase in fragmented peat's content of air/peat flow and, respectively, will promote 
performance improvement for peat harvesting enterprise, the latter being surely its priority task $[10,11]$.

\section{References}

1. O. Misnikov, E3S Web Conf., 21, 01020 (2017)

2. V. V. Panov, O. S. Misnikov, Min. J., 7, 108-112 (2015)

3. R. K. Singh, A. Das, Fuel Processing Technology, 115, 71-78 (2013)

4. Z. N. Gholipour, M. A. Zarringhalam, S. Dorosti, Petroleum \& Coal, 56:2, 188-195 (2014)

5. E. Chertkova, V. Sizova, E3S Web Conf. 105, 01002 (2019)

6. G. Alexandrov, A. Yablonev, E3S Web Conf. 105, 04021 (2019)

7. O. Misnikov, E3S Web of Conf., 41, 01046 (2018)

8. E. A. Kremcheev, D. A. Kremcheeva, Indian Journal of Science and Technology, 9:12, 89525 (2016)

9. K. Singh, AEP Public Land Management, 9, 1-14 (2016)

10. J. Korpi, Proceed. 13-th Int. Peat Cong., Tullamore, Ireland, 1, 120-122 (2008)

11. R. Lindsay, R. Birnie, IUCNUK Committee Peatland Programme, 6, 1-5 (2014) 